\title{
Fauna parasitaria gastrointestinal en polluelos de Pingüino Papua (Pygoscelis papua) encontrados muertos en zona antártica especialmente protegida (ZAEP N¹50)
}

\author{
FERNANDO FREDES*, EDUARDO RAFFO*, PAMELA MUÑOZ* y MARCELA HERRERA**
}

\section{GASTROINTESTINAL PARASITE FAUNA OF NINE GENTOO PENGUIN CHICKS (Pygoscelis papua) FOUND DEAD IN AN ANTARCTIC TERRITORY PROTECTED ZONE}

In the present communication, the presence of Streptocara spp. (Nematoda: Acuariidae) and Contracaecum spp. (Nematoda: Anisakidae) in stomach; two scolex of tapeworms (Cestoda: Cyclophyllida) and eggs of Tetrabothrium spp. (Cestoda: Pseudophyllida) in guts of Gentoo penguin chicks found dead in a protected zone of the Antarctic territory is reported.

Key words: Papua penguin, Streptocara, Tetrabothrius, Antarctic territory.

\section{INTRODUCCIÓN}

Los pingüinos se encuentran protegidos por la República de Chile. Debido a esto, resulta de interés realizar trabajos de investigación que permitan conocer sus enfermedades, para así poder contribuir a su conservación. En Pygoscelis papua sólo existen tres estudios en su hábitat natural y uno de ellos se realizó en nuestro laboratorio entre los años 2000-2001, en otro sector geográfico de la Antártica ${ }^{1}$. El presente trabajo se realizó para aportar información del parasitismo gastrointestinal del pingüino Papua en la Isla Ardley (62 $13^{\prime}$ S, $58^{\circ} 54^{\prime}$ W), península Fildes, isla Rey Jorge, archipiélago Shetland del Sur, territorio Antártico (ZAEP N ${ }^{\circ} 150$ ).

\section{MATERIAL Y MÉTODOS}

El muestreo se realizó durante los meses de enero y febrero del año 2005, en la zona antártica ya mencionada, donde se recolectaron 9 aparatos digestivos completos ligados por compartimiento, todos de pollos muertos en el área de estudio. Todas las muestras fueron recolectadas en envases plásticos y fijadas con formalina al $10 \%$, las que fueron enviadas y almacenadas a $4{ }^{\circ} \mathrm{C}$, en el laboratorio de la unidad de Parasitología del Departamento de Medicina Preventiva Animal de la Facultad de Ciencias Veterinarias y Pecuarias de la Universidad de Chile. El análisis de cada una se realizó mediante observación directa, los métodos cualitativos de flotación y sedimentación ${ }^{2,3}$, además de la técnica de Ziehl Neelsen ${ }^{4}$. En cada muestra positiva a infección parasitaria se procedió a medir, macroscópicamente o con ocular micrométrico, el tamaño aproximado de todos los endoparásitos encontrados (huevos u ooquistes, larvas o adultos) luego fueron registrados gráficamente y

\footnotetext{
* Unidad de Parasitología. Departamento Medicina Preventiva Animal. Facultad de Ciencias Veterinarias y Pecuarias. Universidad de Chile. e-mail: ffredes@uchile.cl

** Instituto Chileno Antártico, proyecto $\mathrm{N}^{\circ} 040$.
} 
posteriormente identificados mediante claves taxonómicas.

\section{RESULTADOS Y DISCUSIÓN}

En los órganos como estómago, el examen directo, evidenció 4 helmintos del tipo Nemathelmintes y de la clase Nematoda, tres del orden Spirurida, familia Acuariidae, sub familia Seuratiinae y género Streptocara; un estadio adulto (Figura 1) y los otros dos estadios juveniles (Figura 2). El otro helminto encontrado fue

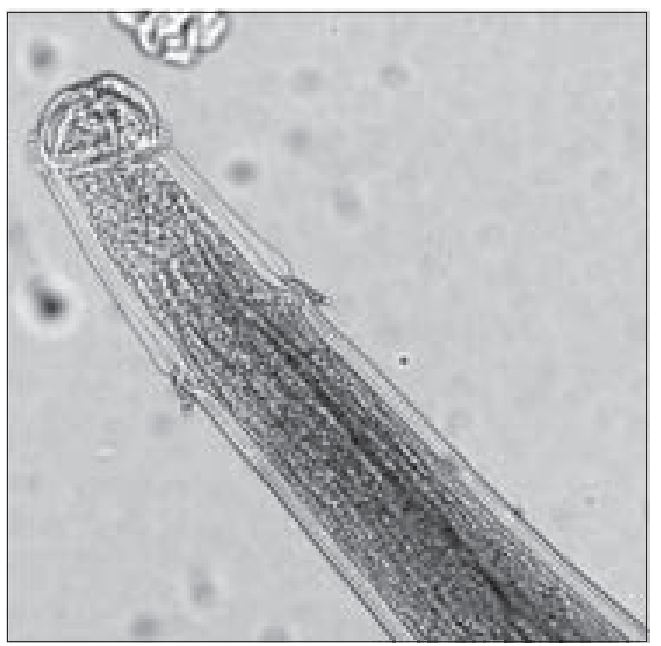

Figura 1. Extremo anterior de un ejemplar de Streptocara spp, encontrado en el estómago de un pollo de pingüino Papua (20x). identificado como del orden Ascaridida, familia Anisakidae y género Contracaecum spp (Figura 3). El resultado del examen de flotación y sedimentación del contenido gástrico fue negativo. En intestino delgado, el examen directo de este órgano, arrojó 2 tipos de helmintos del Tipo Platyhelmintes, de la Clase Cestoda y del Orden Cyclophyllida. Ambos con escólex, uno de ellos armado con ganchos (Figura 4) y el otro con un rostelum no armado (Figura 5), los cuales aún no han sido identificados por carecer de claves adecuadas. El resultado del examen de

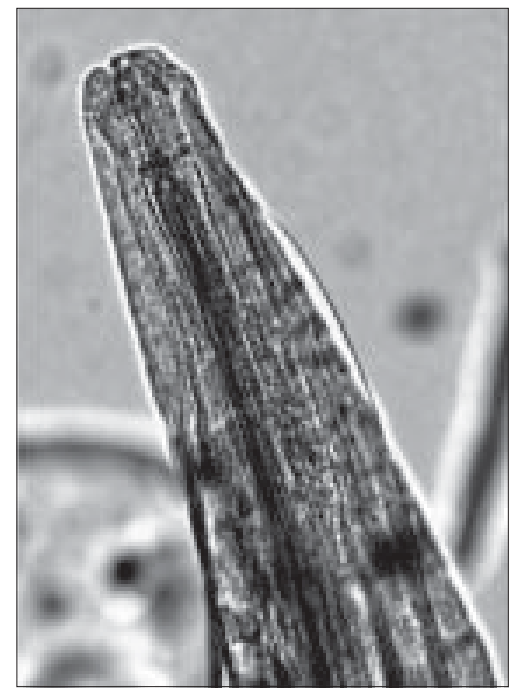

Figura 3. Extremo anterior de un ejemplar de Contracaecum spp, encontrado en el estómago de un pollo de pingüino Papua (20x).

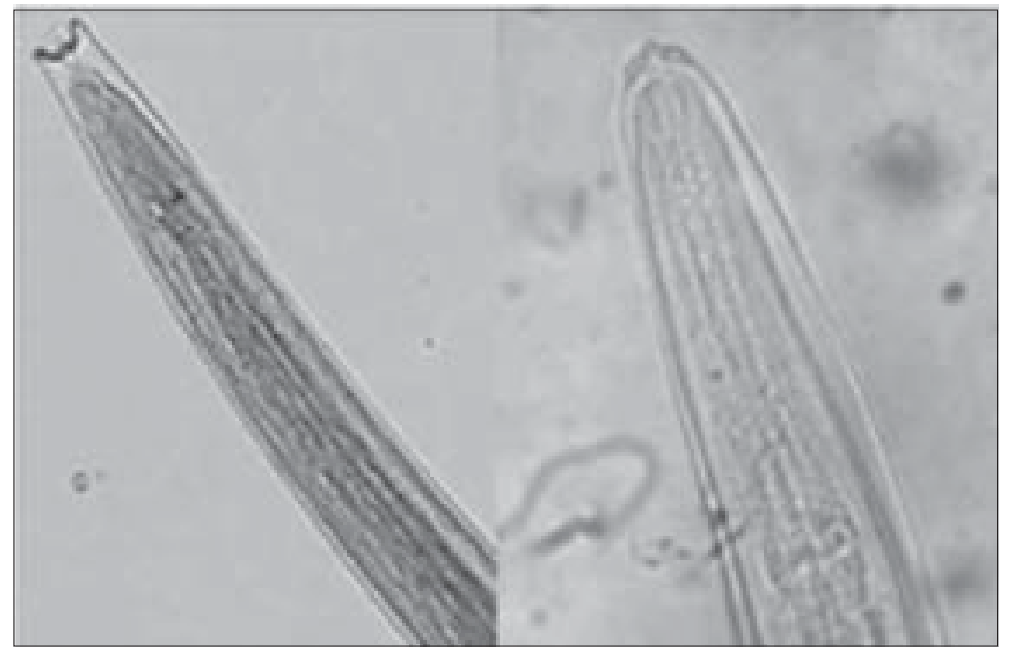

Figura 2. Extremo anterior de dos ejemplares juveniles de Streptocara spp, encontrados en el estómago de un pollo de pingüino Papua $(20 \mathrm{x})$. 


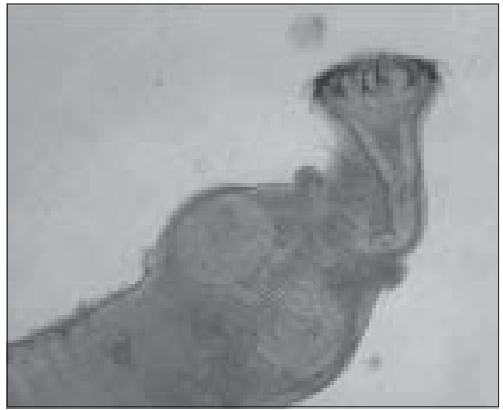

Figura 4. Cestodo encontrado en el intestino delgado de un pollo de pingüino Papua (10x).

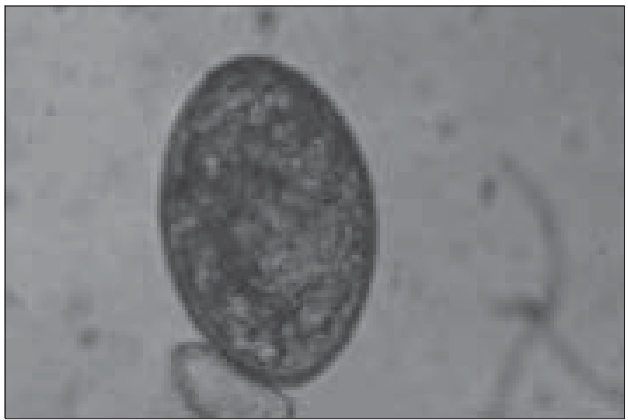

Figura 6. Huevo de Tetrabothrius spp, encontrado en contenido de intestino grueso y ciegos de un pollo de pingüino Papua (40x).

flotación, sedimentación y Ziehl Neelsen del contenido fue negativo. En el intestino grueso y ciegos el examen de flotación resultó positivo, según morfología y tamaño, a huevos del cestodo del Orden Pseudophyllida Tetrabothrius spp. (Figura 6), sin haberse encontrado el adulto en el contenido analizado anteriormente. Los resultados al examen directo, de sedimentación y Ziehl Neelsen fueron negativos.

En relación al nematodo Streptocara, fue muy difícil determinar si ya estaba descrito en esta especie de pingüino, debido a la escasa bibliografía existente en el tema. Sin embargo, encontramos una revisión que indicaba la presencia de este endoparásito en pingüinos, pero lamentablemente no mencionaba la especie de este, ni el lugar donde se reportó. Además al revisar la bibliografía indicada por el mismo autor no coincide con la temática ${ }^{5}$.

El anisakido encontrado vive en la mucosa del proventrículo de pingüinos, causando erosión

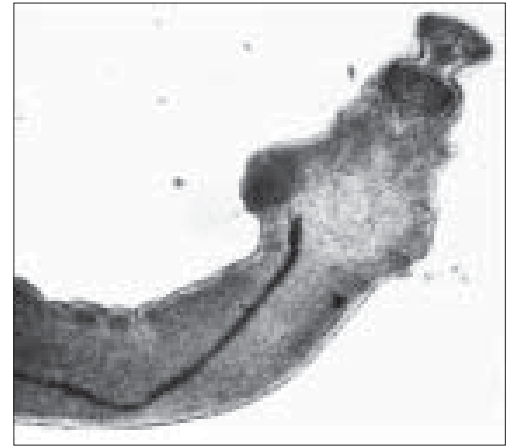

Figura 5. Cestodo encontrado en el intestino delgado de un pollo de pingüino Papua (10x).

y úlceras ${ }^{6}$, y ya ha sido descrito previamente en pingüino papua ${ }^{1,7}$.

Entre los cestodos descritos en el intestino delgado de estas aves, se mencionan la presencia de Tetrabothrius $\operatorname{spp}^{1,8-11}$ y Parochytes zederi ${ }^{8}$, con un ciclo biológico no esclarecido. Aparentemente la carga parasitaria tiende a ser mayor en animales jóvenes más que en adultos y esto se repetiría en todas las especies de pingüinos, tanto en infecciones por cestodos como en las por nematodos ${ }^{8}$.

\section{RESUMEN}

En el presente trabajo, se comunica la presencia de Streptocara spp (Nematoda: Acuariidae) y de Contracaecum spp (Nematoda: Anisakidae) en estómago; de dos escolex de tenias (Cestoda: Cyclophyllida) y huevos de Tetrabothrium spp (Cestoda: Pseudophyllida) en el intestino de pollos de pingüino Papua encontrados muertos en una zona Antártica protegida.

\section{REFERENCIAS}

1.- FREDES F, MADARIAGA C, RAFFO E, et al. Gastrointestinal parasite fauna of gentoo penguins (Pygoscelis papua) from the Península Munita, Bahía Paraíso, Antarctica. Antarctic Science. (Aceptado junio 2006).

2.- THIENPONT D. ROCHETTE F, VAM-PARIJS O. Diagnosing helminthiasis through coprological examination. Beerse, Belgium: Janssen Research Foundation, 1979; $187 \mathrm{pp}$.

3.- SOULSBY E J L. Parasitología y enfer-medades parasitarias en los animales domésticos, 7th ed. México, DF: Inter-americana, 1987; 823 pp. 
4.- DUBEY J, SPEER C A, FAYER R. Cryptosporidiosis of man and animals. Boca Raton, FL: CRC Press, 1990; $199 \mathrm{pp}$.

5.- FOWLER M. Zoo and Wild Animal Medicine. Second Edition. Ed. W.B. Saunders, Philadelphia. 1986; 294313.

6.- OBENDORF D, MCCOLL K. Mortality in little penguins (Eudyptula minor) along the coast of Victoria, Australia. J Wildl Dis, 1980; 16: 251-9.

7.- SANTOS C P. Um nematodeo parasito do pinguim Spheniscus magellanicus (Forter) (Ascaridoidea, Anisakidae). Mem Inst Oswaldo Cruz 1984; 79: 233 7.

8.- CLARKE J, KERRY K. Diseases and Parasites of Penguins. Korean J Polar Res 1993; 4: 79-86.
9.- FOWLER M. Zoo and Wild Animal Medicine. Ed. W.B. Saunders, Philadelphia, 1978; pp 153-64.

10.- JONES H. Notes on Parasites in Penguins (Spheniscidae) and Petrels (Procellariidae) in the Antarctic and Sub-Antarctic. J Wildl Dis 1988; 24: 166-7.

11.- SHELLAM G. Bacterial and Viral Infections of Antarctic Penguins. In: Diseases of Antarctic Wildlife: A Report on the "Workshop on Diseases of Antarctic Wildlife". Australian Antarctic Division, Kingston, Australia. 1998; 112 pp.

Agradecimientos: Financiado por proyecto FIV 2000 y 2005 (Favet, U. de Chile) a quien agradecemos 